\title{
PERANCANGAN SISTEM E-TICKETING BERLANGGANAN BAGI PENUMPANG KOMUTER DAOP 2 BANDUNG
}

\author{
Sri Kuswayati, S.Si.,M.Kom ${ }^{1}$, Sri Erina Damayanti, S.T.,M.Kom² \\ Dosen Prodi Informatika \\ Sekolah Tinggi Teknologi Bandung \\ Email: srikuswayati5@gmail.com erina.damayantie@gmail.com
}

\begin{abstract}
Abstrak: Perancangan Sistem e-ticketing berlangganan bagi Penumpang Komuter DAOP 2 Bandung bertujuan untuk membantu kelancaran aktivitas para penumpang pekerja, mahasiswa atau pelajar serta penumpang umum. Sistem dibuat untuk menghindari antrian dan memberikan prioritas pada penumpang berlangganan. Perancangan sistem dibuat dengan berorientasi objek dengan alat bantu UML. Diharapkan dengan adanya sistem e-ticketing berlangganan tersebut menjadikan penumpang memperoleh kemudahan dalam memperoleh tiket dan mendapat kepastian tempat duduk. Isi ulang dapat dilakukan di loket-loket yang bekerjasama dengan PT KAI. Sistem dapat dikembangkan menjadi lebih mudah diakses dengan berbasis android.
\end{abstract}

Kata Kunci: e-ticketing, $U M L$

\section{Pendahuluan}

Kereta api merupakan alat transportasi masal yang keberadaannya sangat membantu kelancaran aktivitas masyarakat. Keberadaan kereta api bukan saja membantu kebutuhan transportasi jarak jauh semisal antar propinsi, namun juga melayani transportasi jarak dekat.

Komuter adalah sebutan bagi kereta api yang beroperasi dalam jarak dekat yang menghubungkan kota besar dengan kota-kota kecil disekitarnya atau antar dua kota yang berdekatan. Penumpang komuter umumnya adalah warga masyarakat dengan tingkat mobilitas tinggi yang melakukan aktivitas pulang-pergi menggunakan jasa angkutan komuter.

Penumpang yang paling sering menggunakan komuter adalah para pekerja, pelajar dan mahasiswa dimana keberadaan komuter sangat membantu dalam kecepatan dan efisiensi biaya dibanding menggunakan jasa transportasi umum lainnya.

Keberadaan komuter tersebut sangat membantu masyarakat yang tinggal di luar Bandung seperti di wilayah Cicalengka, Padalarang dan Rancaekek yang memiliki pekerjaan atau bersekolah di Bandung.

Kondisi layanan KRD Ekonomi saat ini sudah mengalami banyak peningkatan antara lain sudah tidak ditemukan pedagang asongan di dalam kereta, semua penumpang wajib 
memiliki tiket, tidak ada penumpang yang berdiri dan kondisi kereta bersih terawat serta dilengkapi AC serta pilihan jam keberangkatan hampir terjadi tiap jam sekali.

Meski pemberangkatan terjadi lebih sering (tiap jam) seringkali terjadi antrian di loket dan terdapat penumpang yang kehabisan tiket. Menunggu kereta berangkat pada jam berikutnya akhirnya menjadi pilihan bagi para penumpang yang kehabisan tiket. Bagi penumpang umum menunggu jam keberangkatan satu jam ke depan bukanlah masalah, namun bagi penumpang pekerja dan pelajar serta mahasiswa hal tersebut akan mengakibatkan tiba terlambat di tempat tujuan.

Untuk itu perlu dibuatkan sistem yang mampu mengakomodir kebutuhan penumpang kelas pekerja, pelajar dan mahasiswa agar dapat memiliki kepastian perolehan tempat duduk pada jam-jam mereka berangkat ke tempat kerja atau sekolah serta jam pulang agar mereka tiba di rumah tidak terlalu larut sebab esok harinya harus beraktifitas.

Guna memenuhi kebutuhan tersebut dan mengurangi tingkat antrian di loket pembelian tiket, maka diusulkan adanya sistem e-ticketing berlangganan bagi pemumpang komuter KRD Ekonomi Padalarang-Bandung-Cicalengka. Sistem e-ticketing tersebut berbentuk kartu yang berfungsi sebagai alat input saat penumpang memasuki mesin reader di peron. Manfaat adanya e-ticket tersebut memungkinkan penumpang melakukan isi ulang tiket di loket-loket yang telah bekerja sama dengan KAI. Namun demikian sistem e-ticketing penumpang komuter DAOP 2 Bandung masih memberikan kesempatan kepada penumpang untuk tetap mengisi ulang saldo di loket stasiun.

Tentunya adanya layanan e-ticketing yang bisa memenuhi karakteristik kebutuhan penumpang KRD Ekonomi Padalarang-Bandung-Cicalengka akan sangat membantu kelancaran aktivitas para penumpang pekerja, mahasiswa atau pelajar serta penumpang umum. Sistem e-ticketing yang diberlakukan bagi penumpang KRD Ekonomi Padalarang-Bandung-Cicalengka dibuat khas memenuhi kebutuhan penumpang.

\section{Kelemahan yang terdapat dalam sistem tiket manual yang berjalan adalah :}

a. Penumpang seringkali kehabisan tiket terutama pada jam-jam pergi dan pulang sekolah atau bekerja.

b. Antrian yang panjang membuat para penumpang harus tiba lebih awal agar tak kehabisan tiket, padahal bagi pelajar dan mahasiswa maupun pekerja seringkali mereka tidak memiliki waktu mengantri lebih awal.

c. Jika para siswa, mahasiswa dan karyawan kehabisan tiket mereka terpaksa naik angkutan umum yang sering terganggu kelancarannya akibat kemacetan atau banjir dan juga menggunakan jasa angkutan umum memakan biaya besar. Akibatnya produktivitas menurun, pabrik dirugikan dan mahasiswa atau siswa tak dapat mengikuti kegiatan akademik dengan lancar.

\section{Batasan Masalah}

Mengingat terbatasnya waktu, maka pembahasan difokuskan pada pembuatan Sistem eTicketing Berlangganan Penumpang KRD Ekonomi Padalarang-Bandung- 
Cicalengka. Kata berlangganan di sini dimaksudkan bahwa penumpang adalah mereka yang memang menggunakan komuter untuk transportasi harian. Dengan memberlakukan sistem ticketing berlangganan PT. KAI telah melakukan langkah maju yakni memberikan jaminan tersedianya tiket bagi pengguna komuter dari kalangan pekerja, pelajar dan mahasiswa. Menurunkan tingkat kemacetan dan menumbuhkan kecintaan untuk menggunakan transportasi umum dalam mendukung kelancaran aktivitas harian.

\section{Tinjauan Pustaka}

\subsection{Sistem E-Ticketing}

E-ticketing atau electronic ticketing adalah suatu proses transaksi untuk membayar aktivitas perjalanan pelanggan tanpa uang tunai. Semua informasi mengenai electronic ticketing disimpan secara digital dalam sistem. E-ticketing merupakan sebuah metode perdagangan, pembelian, dan penjualan tiket dari berbagai produk jasa khususnya jasa perjalanan melalui media internet dan komputer.

Menurut Ng-Kruelle dan Swatman [1] E-ticketing atau electronic ticketing adalah suatu cara untuk mendokumentasikan proses penjualan dari aktifitas perjalanan pelanggan tanpa harus mengeluarkan dokumen berharga secara fisik ataupun paper ticket. Semua informasi mengenai electronic ticketing disimpan secara digital dalam sistem komputer milik airline. Sebagai bukti pengeluaran E-Ticket, pelanggan akan diberikan Itinerary Receipt yang hanya berlaku sebagai alat untuk masuk ke dalam bandara di Indonesia. Eticketing(ET) adalah peluang untuk meminimalkan biaya dan mengoptimalkan kenyamanan penumpang. E-ticketing mengurangi biaya proses tiket, menghilangkan fomulir kertas dan meningkatkan fleksibilitas penumpang dan agen perjalanan dalam membuat perubahan-perubahan dalam jadwal perjalanan.

Dari beberapa pengertian diatas maka dapat ditarik kesimpulan bahwa $e$ ticketing merupakan suatu bentuk pelayanan yang diberikan perusahaan jasa kepada konsumen untuk mempermudah melakukan pemesanan tiket yang memanfaatkan media intranet sebagai media transaksi jual beli.

\subsection{Manfaat E-Ticketing}

E-ticketing menyediakan banyak manfaat. Pertama, mampu mengurangi biaya yang terkait dengan pencetakan tiket. Kedua, adalah efisiensi tenaga kerja yakni mengurangi biaya pembayaran tenaga kerja yang terkait dengan pencetakan dan mailing tiket. Ketiga, adanya barcode menghilangkan kemungkinan adanya pemalsuan dan duplikat tiket [2].

Penjualan tiket melalui website bisa memproses ribuan pesanan tiket perhari. Hal tersebut mengakibatkan lebih banyak customer dapat melakukan transaksi. Penjual tidak perlu mengeluarkan biaya untuk menyewa atau menggaji karyawan costumer service. Bagi perusahaan sendiri, E-Ticketing juga memperkecil biaya pelayanan, sehingga harga 
tiket juga dapat ditekan. Konsumen terhindar dari kehilangan tiket secara fisik, karena pada dasarnya, setelah kode booking di konfirmasi, nama konsumen telah tercatat di sistem.

\subsection{Siklus Hidup Pengembangan Sistem Berorientasi Objek}

Adi Nugroho (2005) menjelaskan bahwa siklus hidup pengembangan sistem/perangkat lunak berorientasi objek mengandung 3 proses makro : analisis berorientasi objek, perancangan berorientasi objek, dan implementasi berorientasi objek [3]. Model use case dapat dipergunakan sebagai pemandu pada hampir semua aktivitas pengembangan perangkat lunak mulai dari tahapan analisis, perancangan, implementasi, serta pengujian.

Analisis berorientasi objek (OOA-Object Oriented Analysis) adalah tahapan perangkat lunak dengan menentukan spesifikasi sistem (sering orang menyebutnya sebagai SRS (System Requirement Spesification) dan mengidentifikasi kelas-kelas serta hubungannya satu terhadap yang lain.

Untuk memahami spesifikasi sistem kita perlu mengidentifikasi para pengguna atau yang sering disebut sebagai aktor-aktor. Ivar Jacobson memperkenalkan konsep use case sebagai skenario untuk menjelaskan interaksi pengguna dengan sistem. Model use case menggambarkan pandangan pengguna atau kebutuhan pengguna.

Sasaran dari perancangan berorientasi objek (OOD-Object Oriented Design) adalah merancang kelas-kelas yang teridentifikasi selama tahap analisis dan antarmuka pengguna. Selama tahap ini mengidentifikasi dan menambah beberapa objek dan kelas yang mendukung implementasi dan spesifikasi kebutuhan. Perancangan berbasis objek dan analisis berorientasi objek adalah topik-topik yang terpisah namun keduanya saling bekerja sama dengan erat. Aktivitas dan fokus dari analisis berorientasi objek dan perancangan berbasis objek saling bekerja sama, saling melengkapi.

\subsection{UML}

Unified Modelling Language (UML) adalah salah satu alat bantu yang sangat handal didunia pengembangan sistem yang berorientasi obyek[4]. Hal ini disebabkan karena UML menyediakan bahasa pemodelan visual yang memungkinkan bagi pengembang sistem untuk membuat cetak biru atas visi mereka dalam bentuk yang baku, mudah dimengerti serta dilengkapi dengan mekanisme yang efektif untuk berbagi (sharing) dan mengkomunikasikan rancangan mereka dengan yang lain. UML merupakan kesatuan dari bahasa pemodelan yang dikembangkan oleh Booch, Object Modeling Technique (OMT) dan Object Oriented Software Engineering (OOSE) . Metode Booch dari Grady Booch sangat terkenal dengan nama Metode Design Object Oriented.

Untuk perancangan sebuah aplikasi dengaan menggunakan UML, UML mempunyai sejumlah elemen grafis yang bisa dikombinasikan menjadi diagram. Tipe diagram UML dapat dilihat pada table berikut ini. 
Tabel 1. Tipe Diagram UML

\begin{tabular}{|l|l|}
\hline \multicolumn{1}{|c|}{ Diagram } & \\
\hline Activity & Perilaku prosedural dan paralel \\
\hline Class & Class, Fitur dan relasinya \\
\hline Communication & Interaksi diantara obyek. Lebih menekankan ke \\
& Link \\
\hline Component & Struktur dan koneksi dari komponen \\
\hline & \\
\hline Composite structure & Dekomposisi sebuah class saat runtime \\
\hline Deployment & Penyebaran/ instalasi ke klien \\
\hline Interaction Overview & Gabungan antara activity dan sequence diagram \\
\hline Object & Contoh konfigurasi instance \\
\hline Package & Struktur hierarki saat kompilasi \\
\hline Sequence & $\begin{array}{l}\text { Interaksi antara obyek. Lebih menekankan pada } \\
\text { urutan }\end{array}$ \\
\hline State Machine & Bagaimana event mengubah sebuah obyek \\
\hline Timing & Interkasi antara obyek. Lebih menekankan pada \\
\hline & watu \\
\hline Use Case & Bagaimana User berintaraksi dengan sistem \\
\hline
\end{tabular}




\section{Pembahasan}

\subsection{Use Case Diagram}

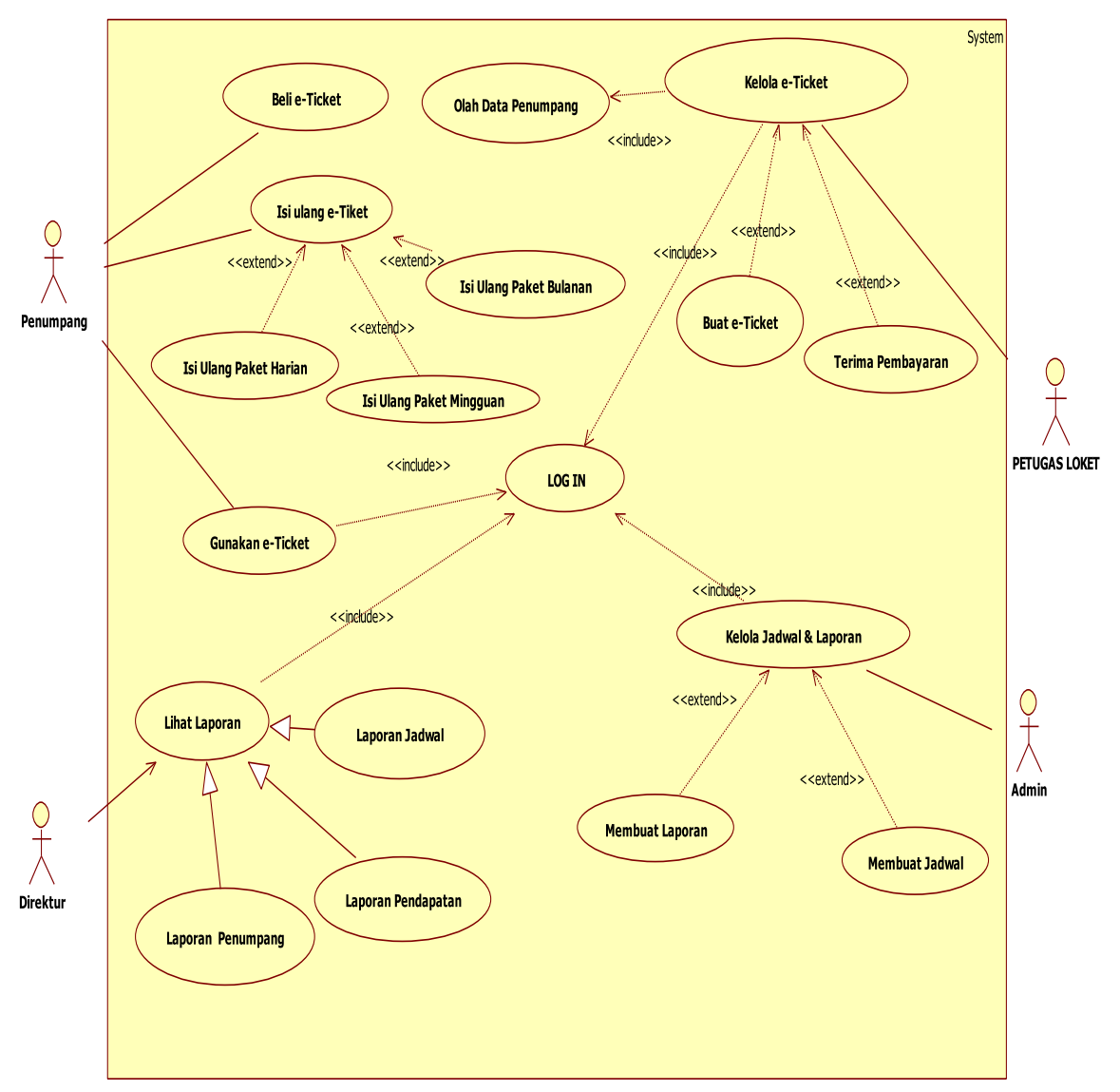

Gambar 1. Usecase diagram Sistem e-Ticket

\subsubsection{Deskripsi Use Case Diagram}

\section{Tabel 2. Deskripsi Use Case Diagram}

\begin{tabular}{|l|l|l|}
\hline Use Case : & Actor & Deskripsi \\
\hline 1. Beli e-Ticket & Penumpang \& & Penumpang melakukan pembelian e- \\
& Petugas Loket & $\begin{array}{l}\text { Tiket di loket dibantu petugas loket. } \\
\text { Caranya adalah dengan menyerahkan }\end{array}$ \\
& & $\begin{array}{l}\text { KTP sebagai data awal yang akan } \\
\text { diinputkan petugas ke dalam sistem. }\end{array}$ \\
\hline
\end{tabular}




\begin{tabular}{|l|l|l|}
\hline & & $\begin{array}{l}\text { Kemudian petugas loket akan mencetak } \\
\text { e-Ticket. }\end{array}$ \\
\hline $\begin{array}{c}\text { 2. Isi ulang } \\
\text { e-Ticket }\end{array}$ & $\begin{array}{l}\text { Penumpang \& } \\
\text { Petugas Loket }\end{array}$ & $\begin{array}{l}\text { Penumpang melakukan isi ulang } \\
\text { e-Ticket di loket dibantu petugas loket } \\
\text { dengan pilihan : paket harian, mingguan } \\
\text { atau bulanan }\end{array}$ \\
\hline $\begin{array}{l}\text { 3. Gunakan } \\
\text { e-Ticket }\end{array}$ & Penumpang & $\begin{array}{l}\text { Penumpang menggunakan } \\
\text { e-Ticket saat akan melakukan perjalanan } \\
\text { menggunakan Kereta Api. Cara yang } \\
\text { dilakukan adalah dengan memasukkan } \\
\text { tiket ke dalam mesin yang terdapat di } \\
\text { peron. }\end{array}$ \\
\hline $\begin{array}{l}\text { 4. Kelola } \\
\text { e-Ticket }\end{array}$ & Petugas Loket & $\begin{array}{l}\text { Petugas melakukan LOGIN ke sistem } \\
\text { kemudian melakukan pembuatan e- } \\
\text { Ticket dan menerima pembayaran atas } \\
\text { pembuatan e-Ticket serta isi ulang e- } \\
\text { Ticket }\end{array}$ \\
\hline $\begin{array}{l}\text { 5. Kelola } \\
\text { Jadwal \& } \\
\text { Laporan }\end{array}$ & Admin & $\begin{array}{l}\text { Admin melakukan LOGIN sistem } \\
\text { kemudian melakukan inputan jadwal } \\
\text { serta membuat laporan dari data yang } \\
\text { tersimpan di sistem. }\end{array}$ \\
\hline 6. Lihat Laporan \\
Direktur & $\begin{array}{l}\text { Direktur melakukan LOGIN sistem } \\
\text { kemudian melihat Laporan Penumpang, } \\
\text { Laporan Pendapatan dan Laporan } \\
\text { Jadwal. }\end{array}$ \\
\hline
\end{tabular}

\subsection{Activity Diagram}

\section{a. Activity Diagram Beli e-Ticket}




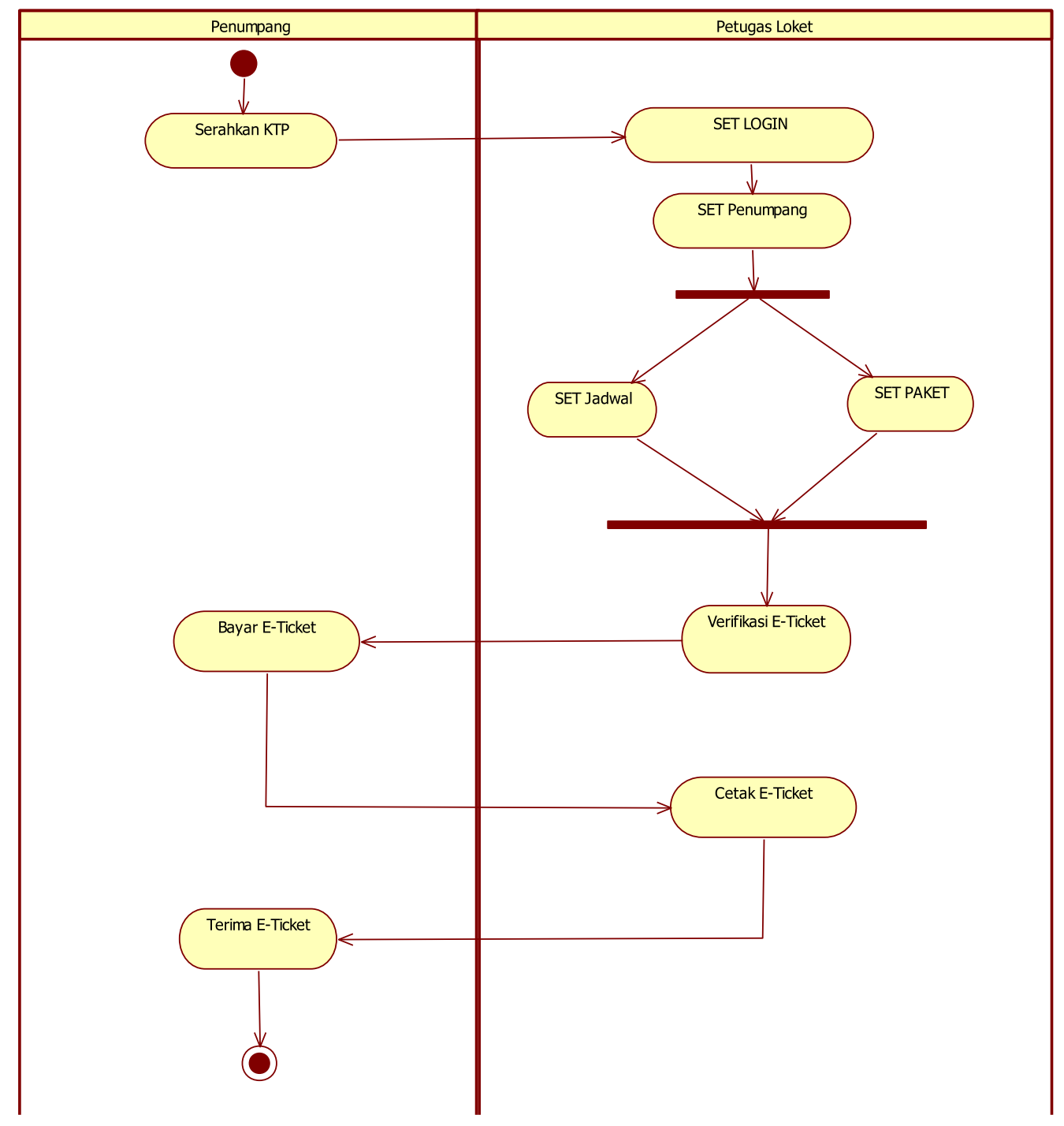

Gambar 2. Activity Diagram Beli e-Ticket 


\section{b. Activity Diagram Isi ulang e-Ticket}

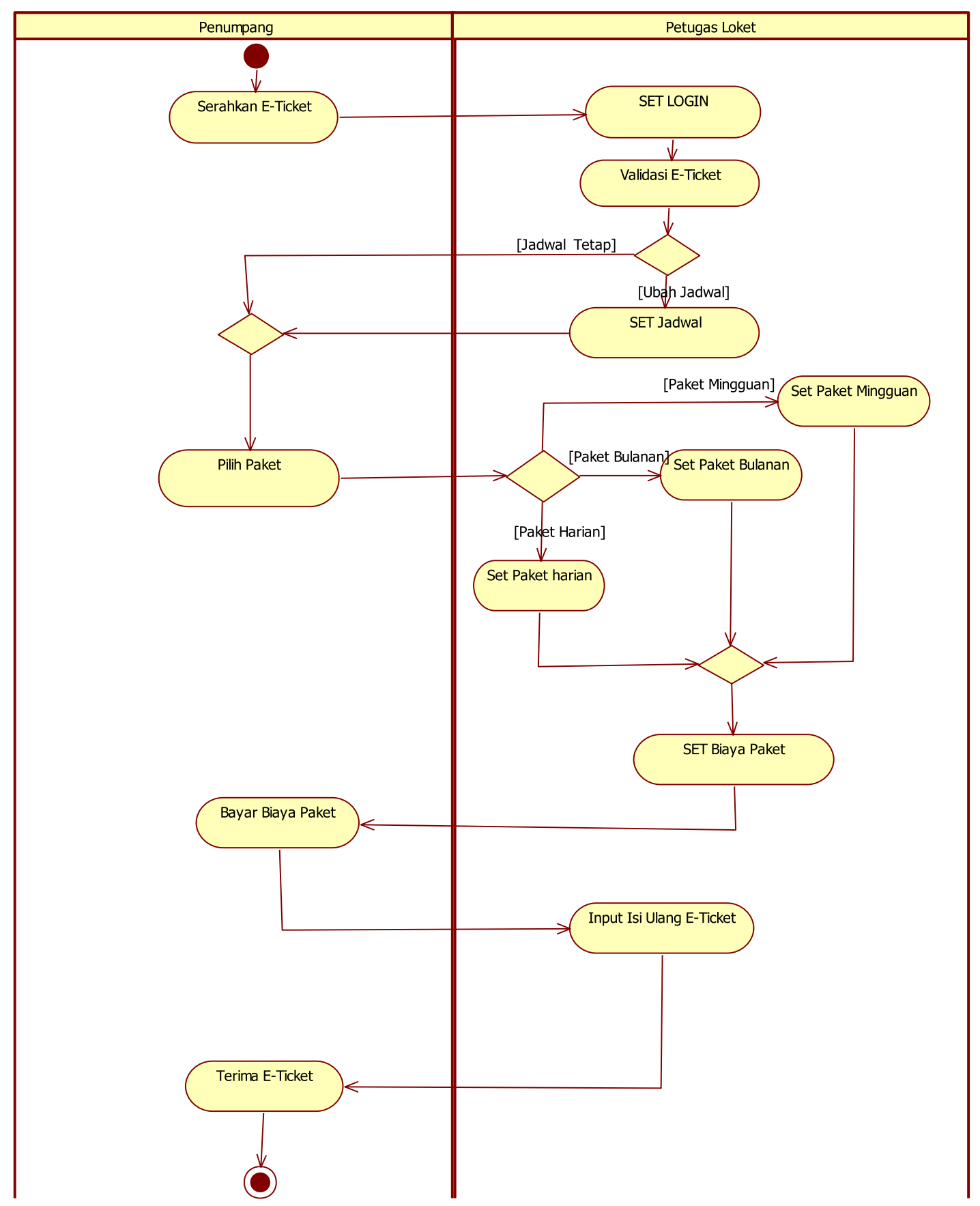

Gambar 3. Activity Diagram Isi Ulang e-Ticket 


\section{c. Activity Diagram Gunakan e-Ticket}

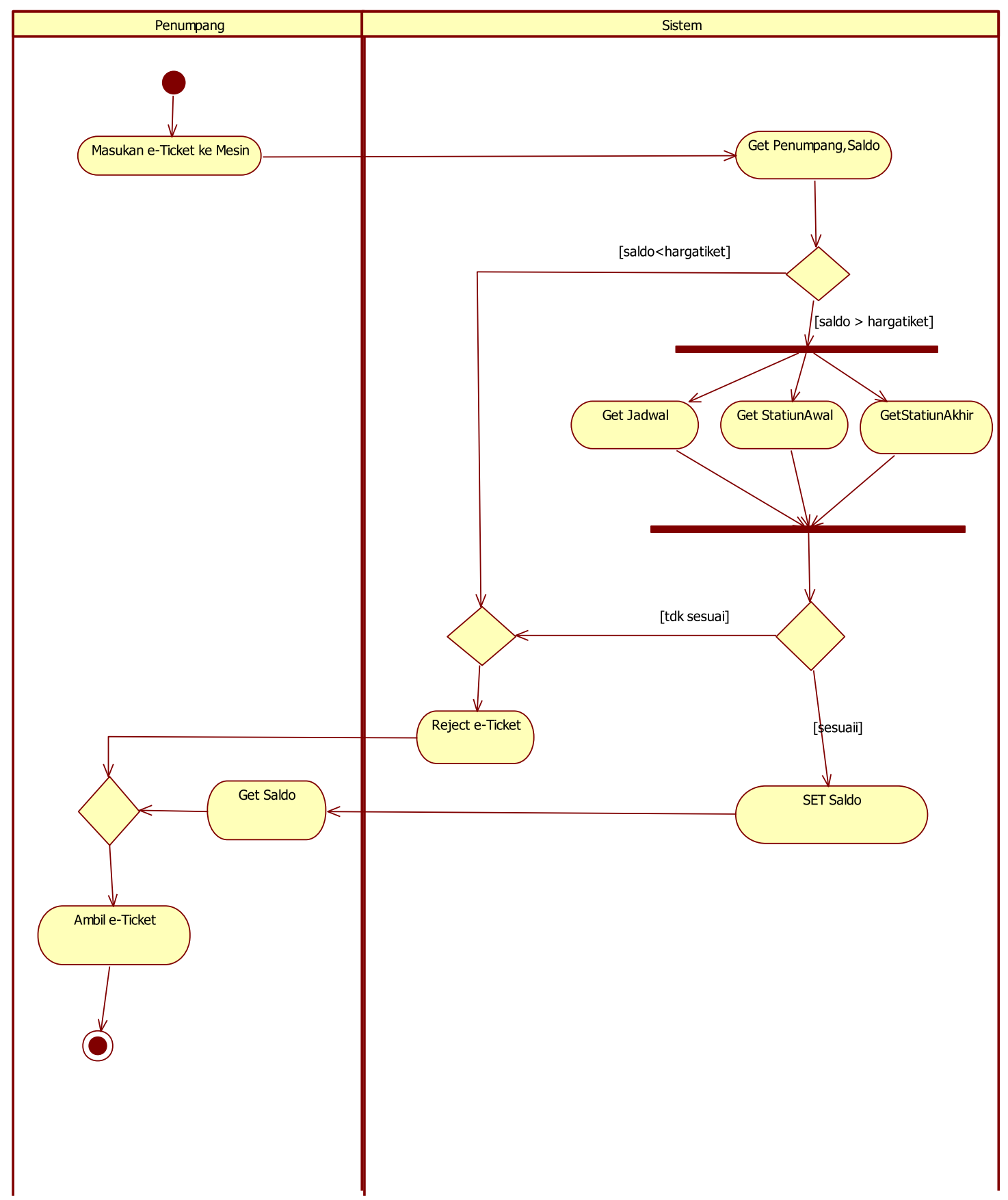

Gambar 4. Activity Diagram Gunakan e-Ticket 


\section{d. Activity Diagram Kelola e-Ticket}

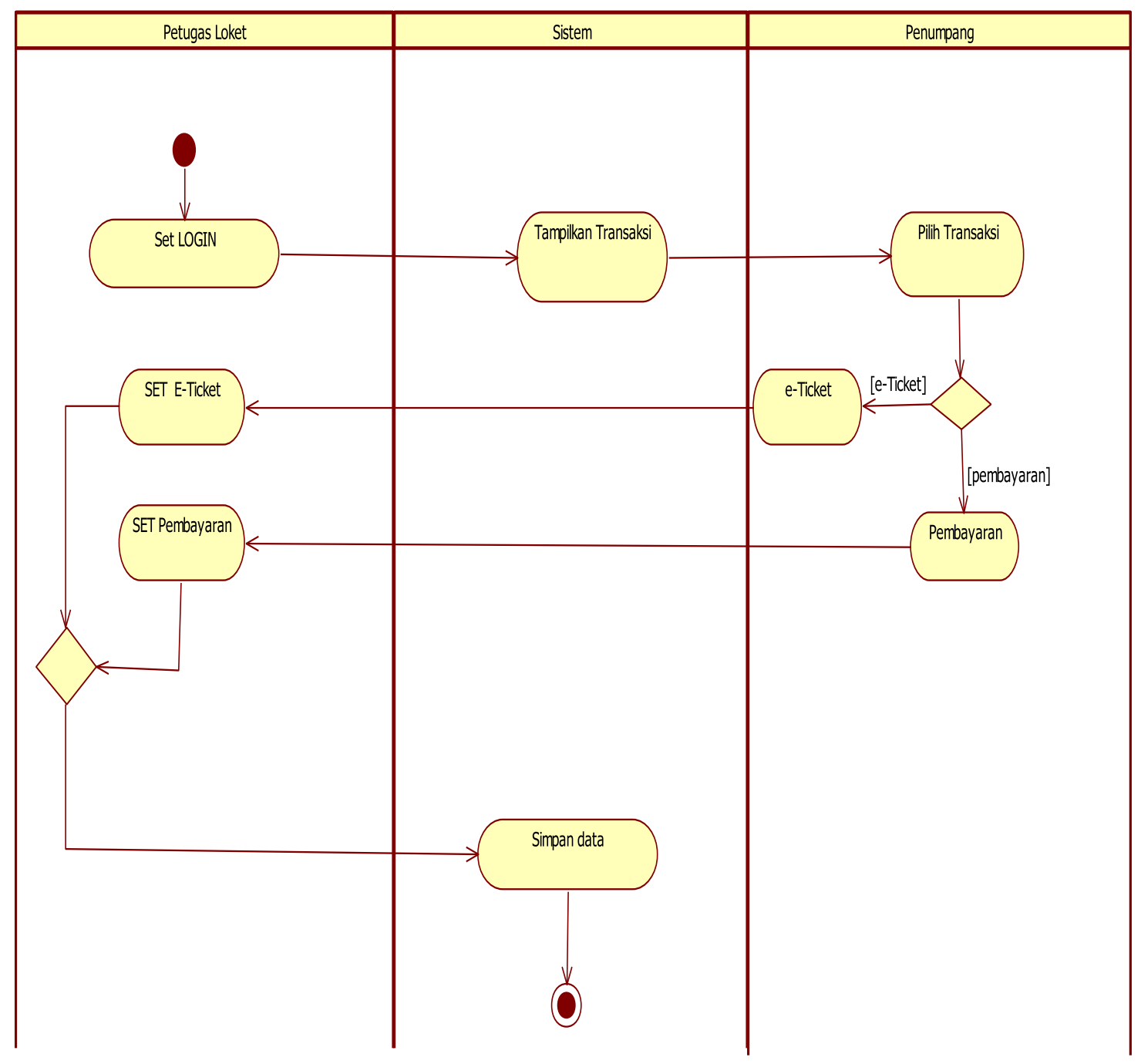

Gambar 5. Activity Diagram Kelola e-Ticket

\section{e. Activity Diagram Kelola Jadwal \& Laporan}




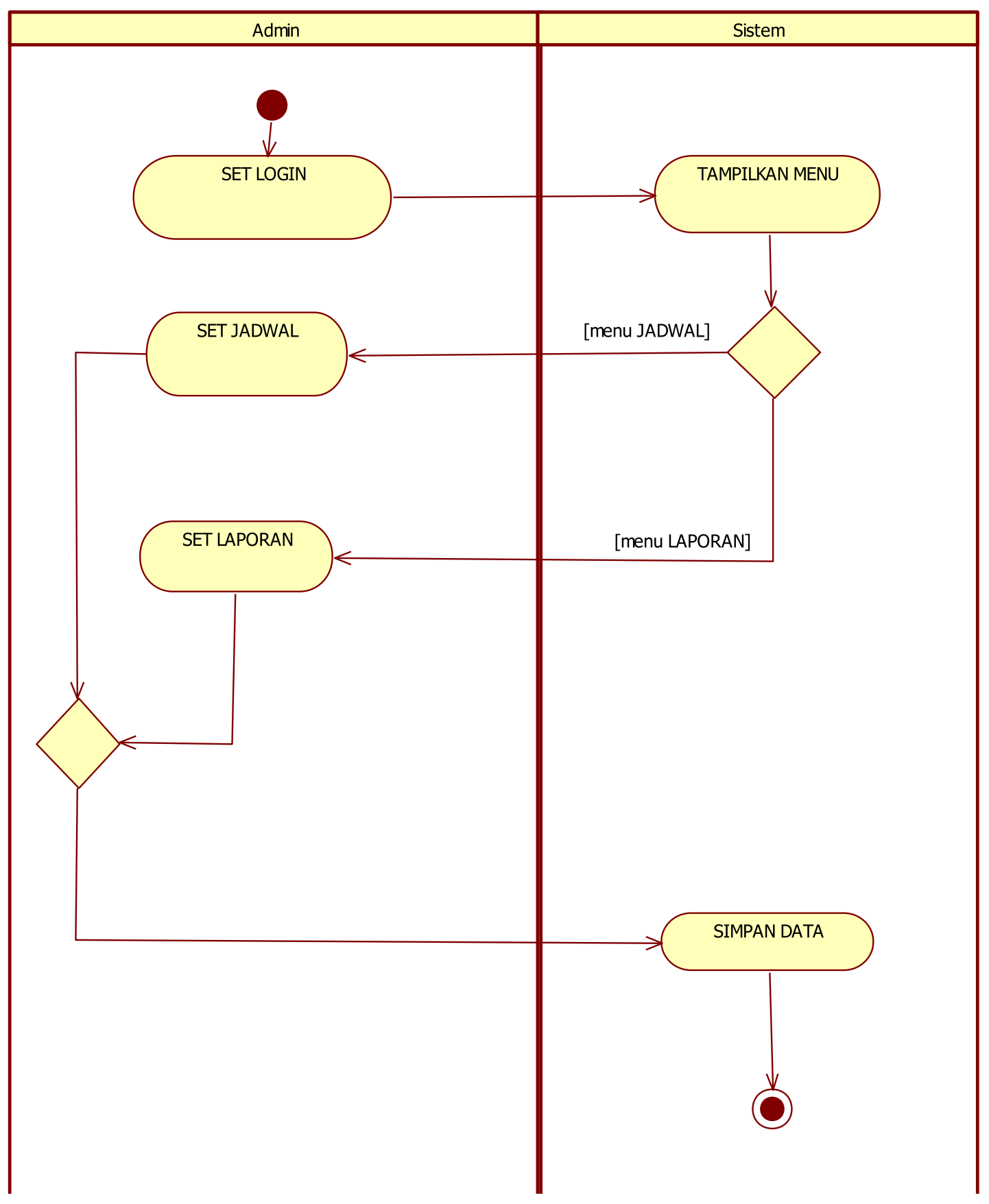

Gambar 6. Activity Diagram Kelola Jadwal dan Laporan e-Ticket 


\section{f. Activity Diagram Lihat Laporan}

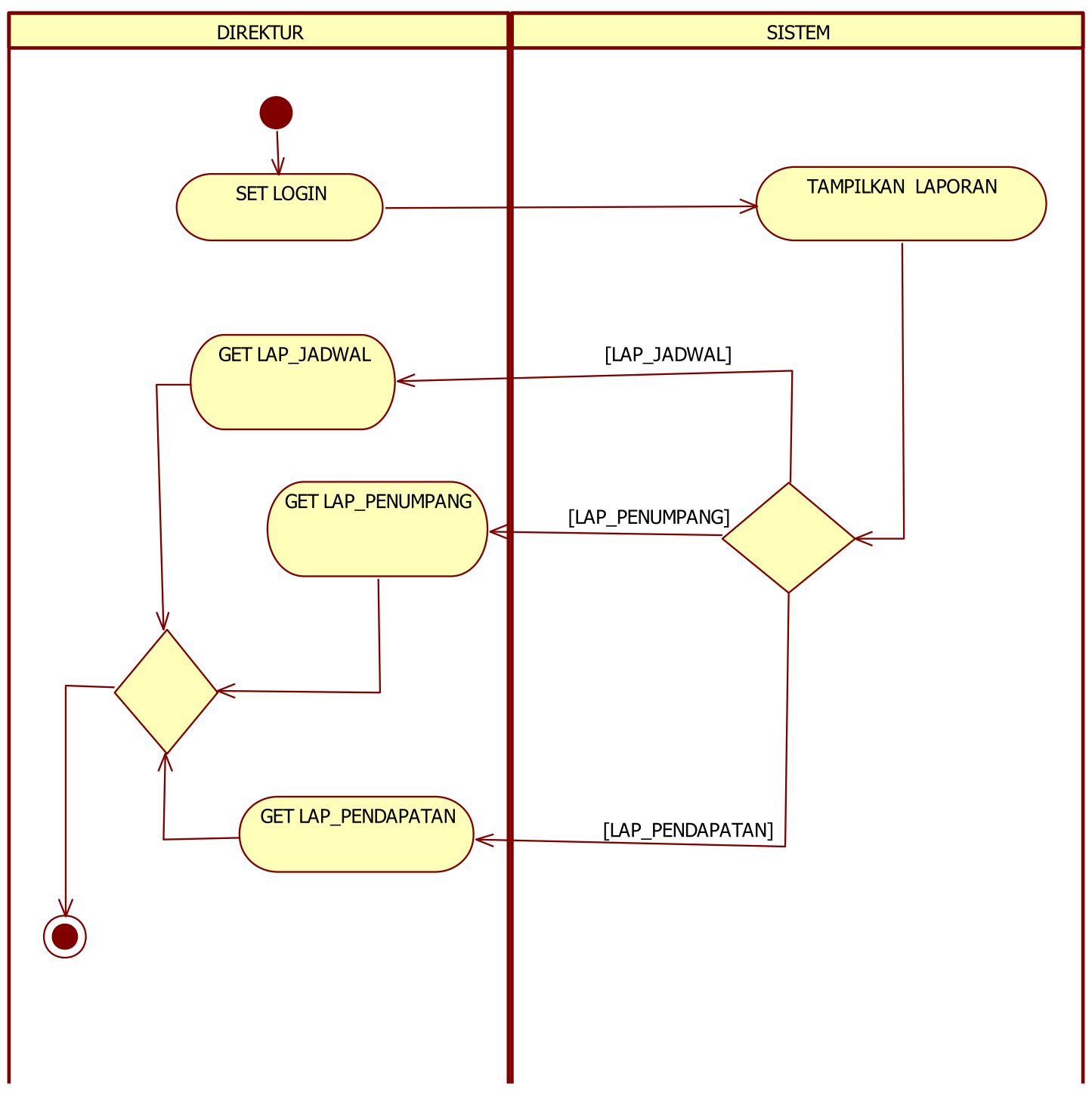

Gambar 7. Activity Diagram Lihat Laporan 


\subsection{Class Diagram}

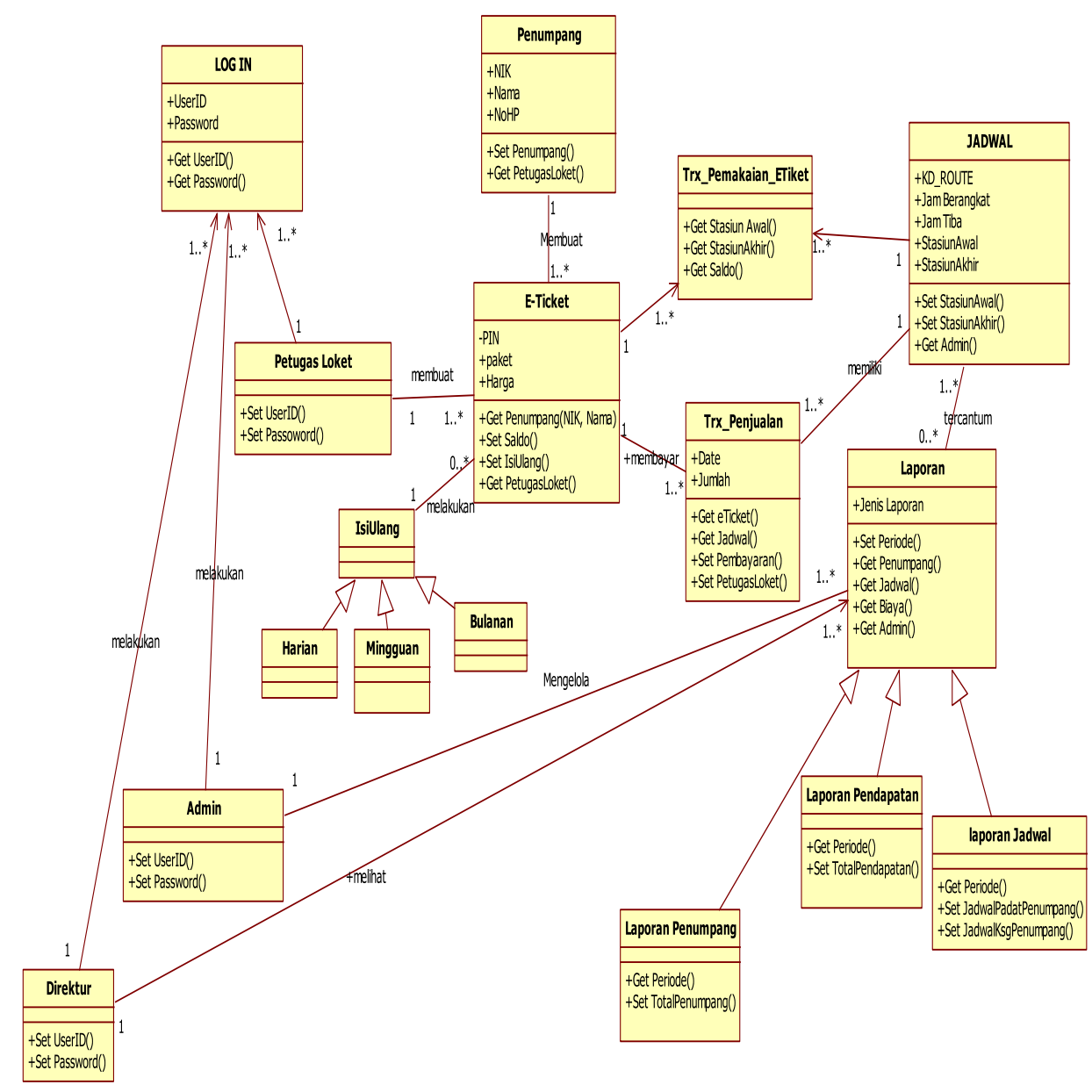

Gambar 8. Class Diagram e-Ticket

\section{Kesimpulan dan Saran}

\subsection{Kesimpulan}

Perancangan sistem yang dibuat mampu menjawab kebutuhan penumpang dalam hal :

a. Sistem pembayaran e-Ticket

Terdapat 3 pilihan pembayaran e-ticket yakni harian, mingguan dan bulanan.

Pembayaran dapat langsung dilakukan di loket-loket yang telah bekerja sama dengan PT KAI atau langsung di loket stasiun. Hal tersebut sangat memudahkan penumpang KRD Ekonomi Padalarang-Bandung-Cicalengka. Dengan melakukan pembayaran sistem mingguan dan bulanan maka para pelanggan komuter DAOP 2 Bandung ini tak perlu mengantri karena nama mereka tercatat sebagai penumpang di sistem.

b. Memangkas waktu antrian 
Dengan adanya e-Ticketing penumpang cukup mengantri untuk registrasi tiket baru. Diluar hal tersebut penumpang dapat langsung membawa tiket ke pintu peron yang telah dilengkapi alat pembaca e-ticketing. Jika terpaksa harus mengantri di loket, petugas loket tinggal menginputkan nomor kartu untuk kemudian data-data pemilik kartu akan ditampilkan secara otomatis.

c. Menghindari kerugian PT KAI

Sistem e-Ticketing Berlangganan Penumpang KRD Ekonomi Padalarang-BandungCicalengka merekam data penumpang di sistem sehingga jika suatu saat penumpang e-ticketing berlangganan ketinggalan kartu cukup menyebutkan NIK yang terdapat di KTP dan memperlihatkan KTP asli pada petugas jaga mesin peron. Hal tersebut dimungkinkan karena nomor tiket yang dibuat merujuk pada NIK penumpang. Dalam sistem yang dibuat, penumpang hanya cukup memeriksakan tiket di mesin yang terdapat pada peron awal pemberangkatan sehingga menghindari oknum penumpang harian membawa pulang e-Ticket.

d. Memudahkan pihak manajemen dalam mengambil keputusan

Dari pembacaan e-ticketing di mesin yang terdapat di peron tersebut dapat diperoleh informasi akurat tanggal pemakaian e-ticket, stasiun keberangkatan dan stasiun pemberhentian. Dari data penumpang yang terekam di sistem beserta data transaski pemakaian e-ticketing pihak Direktur akan cepat memperolah informasi karakteristik penumpang, jumlah uang yang masuk serta kepadatan tiap jalur. Dari informasi yang diperoleh pihak manajemen selanjutnya dapat mengambil langkah strategis guna perbaikan kulitas layanan dan meningkatkan pendapatan PT KAI.

\subsection{Saran}

Saran bagi pengembangan aplikasi e-Ticketing selanjutnya adalah sebagai berikut :

a. Sistem e-ticketing dapat dikembangkan menjadi sistem berbasis android

b. Pengembangan sistem berbasis android diharapkan memberikan kemudahan pada pelanggan untuk melakukan akses.

\section{Daftar Pustaka}

[1] G. Ng-Kruelle and P. A. Swatman. e-Ticketing Strategy and Implementation in an Open Access System: The case of Deutsche Bahn," reasearchgate.net, 2006.

[2] Gushelmi, Deded Ramad Kamda. Pemodelan UML Sistem Berbasis WAP. Jurnal Ilmu Komputer, Vol.1,No.1, Oktober 2012

[3] Nugroho, Adi. 2005. Analisa dan Perancangan Sistem Informasi dengan Metodologi Berorientasi Objek. Informatika: Bandung.

[4] Munawar. 2005. Pemodelan Visual Dengan UML. Graha Ilmu. Yogyakarta

[5] www.merdeka.com, diakes pada tanggal diakses pada tanggal 3/10/2017 jam 09.00

[6] https://student.cnnindonesia.com diakses pada tanggal 3/10/2017 jam 09.00 